\title{
AKTIVITAS ANTIKANKER SENYAWA PTEROKARPAN DARI Erythrina fusca L.
}

\author{
Novi Anggreini $^{1)}$, Ratih Dewi Saputri ${ }^{1)}$, Tjitjik Srie Tjahjandarie ${ }^{1)}$, Mulyadi Tanjung ${ }^{1 *}$ \\ ${ }^{1)}$ Natural Products Chemistry Research Group, Organic Chemistry Division, \\ Department of Chemistry, Faculty of Science and Technology, Universitas Airlangga, Surabaya \\ 60115 , Indonesia \\ mulyadi-t@fst.unair.ac.id
}

\begin{abstract}
Two pterocarpans namely as sandwicensin (1) dan phaseollin (2) were isolated from the stem bark of. Erythrina fusca L. Their structures were determined based on spectroscopic data such as UV, IR, MS, ID and 2D NMR. Compounds 1-2 were evaluated for their anticancer against murin leukemia P-388 cells showing their $I C_{50}$ were 1.20 and $1.05 \mu \mathrm{g} / \mathrm{ml}$, respectively and very high activity.

Keywords : Erythrina fusca L., sandwicensin, phaseollin, anticancer
\end{abstract}

\begin{abstract}
ABSTRAK
Dua senyawa pterokarpan yakni sandwisensin (1) dan paseollin (2) telah diisolasi dari kulit batang Erythrina fusca L. Struktur senyawa pterokarpan ditetapkan berdasarkan analisis spektroskopi UV, IR, MS, 1D dan 2D NMR. Uji aktivitas antikanker senyawa 1-2 terhadap sel murin leukemia P388 memperlihatkan $\mathrm{IC}_{50} 1,20$ dan $1,05 \mu \mathrm{g} / \mathrm{ml}$ yang dikategorikan sangat aktif.
\end{abstract}

Kata kunci : Erythrina fusca L., sandwisensin, paesolin, antikanker

Novi Anggreini dkk... 


\section{PENDAHULUAN}

Erythrina fusca L. merupakan salah satu spesies famili Leguminosae yang dikenal dengan nama dadap cangkring. Pemanfaatan tumbuhan ini digunakan masyarakat sebagai obat demam, sakit gigi, batuk, dan malaria (Heyne, 1987). Pterokarpan dan flavonoid merupakan senyawa fenolik utama pada genus Erythrina. Ciri khas senyawa pterokarpan pada genus Erythrina mempunyai substituen isoprenil $\left(\mathrm{C}_{5}\right)$ dan geranil $\left(\mathrm{C}_{10}\right)$ yang terikat pada inti aromatik flavonoid. Senyawa pterokarpan Erythrina memperlihatkan aktivitas biologis yang menarik antara lain sebagai antimalaria dan antikanker (Khaomek, 2008; Innok, 2010; Tjahjandarie, 2015; 2014; Yenesew, 2004).

Kanker merupakan salah satu penyakit yang menyebabkan kematian setelah jantung. Jumlah penderita kanker diperkirakan meningkat tiap tahun. Di samping itu, produksi vinkristin dan taksol sebagai obat kanker tidak signifikan dengan jumlah penderita kanker. Oleh karena itu, eksplorasi senyawa aktif yang dapat menghambat atau membunuh sel kanker sebagai kandidat obat kanker baru.

Penelitian ini bertujuan untuk mengisolasi dan mengidentifikasi senyawa pterokarpan dari kulit batang Erythrina fusca L. Pada kesempatan kali ini akan dilaporkan penemuan dua senyawa flavanon terisoprenilasi, yakni sandwisensin (1) dan paseollin (2) dari kulit batang E. fusca L. Disamping itu, aktivitas antikanker kedua senyawa pterokarpan terhadap terhadap sel murin leukemia P-388 juga akan dibahas.

\section{METODE PENELITIAN Prosedur umum}

Spektrum UV ditetapkan dengan spektrofotometer UV-Vis Shimadzu 1800. Spektrum IR ditentukan dengan spektrofotometer IR Perkin Elmer. Spektrum massa ditentukan dengan spektrometer HR-ESI-MS merck Waters LCT XE ESI. Spektrum NMR ditentukan dengan spektrometer NMR JEOL ECA 400 yang beroperasi pada $400 \mathrm{MHz}\left({ }^{1} \mathrm{H}-\right.$ NMR) dan $100 \mathrm{MHz}$ ( $\left.{ }^{13} \mathrm{C}-\mathrm{NMR}\right)$. Kromatografi kolom gravitasi menggunakan silika gel 60 (Merck), kromatografi radial menggunakan silika gel $60 \mathrm{PF}_{254}$ (Merck) dan kromatografi lapis tipis (KLT) menggunakan plat KLT silika gel $60 \mathrm{GF}_{254} 0.25 \mathrm{~mm}$ (Merck).

\section{Sampel penelitian}

Sampel penelitian yang digunakan dalam penelitian berupa kulit batang dari tumbuhan E. fusca L. yang diperoleh dan diidentifikasi di Kebun Raya LIPI Purwodadi, Jawa Timur.

\section{Ekstraksi dan isolasi flavonoid terisoprenilasi}

Ekstraksi kulit batang E. fusca L. sebanyak 2,5 kg menggunakan metanol pada suhu kamar sebanyak dua kali selama 24 jam. Ekstrak metanol yang diperoleh dipekatkan dengan alat penguap bertekanan rendah sehingga diperoleh ekstrak kental metanol berwarna coklat (250 g). Ekstrak metanol selanjutnya dipartisi dengan $n$-heksana menghasilkan ekstrak $n$-heksana dan ekstrak metanol. Ekstrak metanol selanjutnya ditambahkan asam sulfat 5\% pH 3-4 kemudian dipartisi dengan etil asetat menghasilkan ekstrak etil asetat dan fasa asam. Ekstraksi ini bertujuan untuk memisahkan senyawa pterokarpan dan alkaloid (Tanjung; 2017; Tjahjandarie, 2015). Pemisahan ekstrak etil asetat (17 g) dengan kolom vakum cair menggunakan campuran eluen $n$ - 
heksana:etil asetat $(9: 1,8: 2$, dan 1:1) menghasilkan empat fraksi utama A-D. Berdasarkan analisis KLT, fraksi B dengan lampu UV. Pemisahan fraksi B (300 mg) dengan kromatografi kolom gravitasi dengan eluen $n$-heksana:etilasetat (9:1 sampai 7:3) menghasilkan tiga

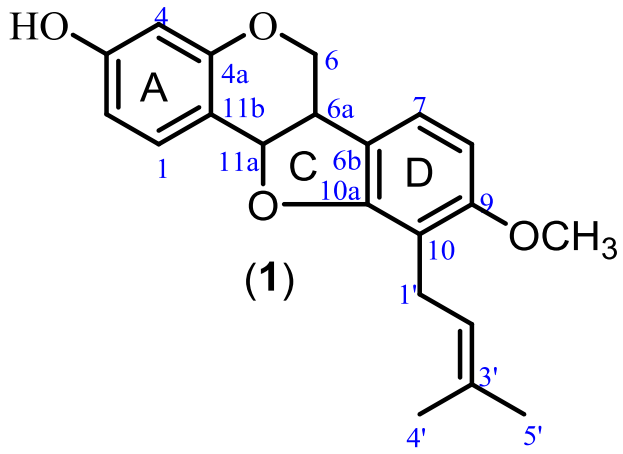
memperlihatkan pendaran warna ungu

subfraksi $\mathrm{B}_{1}-\mathrm{B}_{3}$. Pemurnian subfraksi $\mathrm{B}_{2}$ dilakukan dengan kromatografi radial dengan menggunakan eluen $n$ heksana:aseton $\quad(9: 1 \quad$ sampai $\quad 4: 1)$ menghasilkan senyawa sandwisensin (1) sebanyak $60 \mathrm{mg}$ dan paseollin (2) sebanyak $5 \mathrm{mg}$.

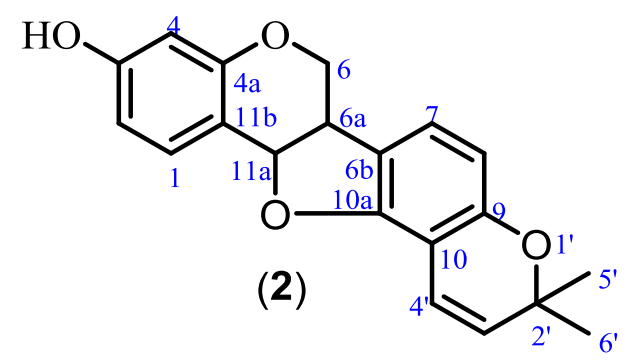

Gambar 1. Struktur sandwisensin (1) dan paseollin (2)

\section{Uji aktivitas antikanker}

Penentuan uji aktivitas antikanker senyawa 1-2 terhadap sel kanker murin leukemia P-388 menggunakan menggunakan metode MTT (Tanjung, 2017; 2010). Penentuan aktivitas antikanker masing-masing senyawa dilarutkan dalam DMSO dan dibuat variasi konsentrasi uji sebanyak triplo $(1000 ; 100$; $30 ; 10 ; 3 ; 1 ; 0,3$ dan $0,1 \mu \mathrm{g} / \mathrm{ml}$ ) kedalam kultur sel kanker. Artonin E digunakan sebagai kontrol positif. Senyawa uji dalam kultur sel diinkubasi selama 48 jam pada suhu $37^{\circ} \mathrm{C}$. Kultur sel yang mengandung senyawa uji ditambahkan larutan MTT dan diinkubasi selama 4 jam pada suhu $37^{\circ} \mathrm{C}$ kemudian ditambahkan larutan penghenti yakni larutan sodium dodesil sulfat. Absorbansi senyawa uji diukur menggunakan microplate reader pada $\lambda 550 \mathrm{~nm}$. Analisis data nilai $\mathrm{IC}_{50}$ ditentukan berdasarkan persentase konsentrasi daya hambat menggunakan program SPSS.

\section{HASIL DAN PEMBAHASAN}

Dua senyawa pterokarpan yakni sandwisensin (1) dan paseollin (2) telah berhasil diisolasi dari ekstrak etil asetat kulit batang E. fusca L. Struktur kedua senyawa ditetapkan berdasarkan spekroskopi UV, IR, MS, 1D dan 2D NMR.

Sandwisensin (1) berwujud padatan putih dan memperlihatkan ion kuasimolekul negatif $[\mathrm{M}-\mathrm{H}]^{-}$pada $\mathrm{m} / \mathrm{z}$ 339,1642 yang sesuai dengan rumus molekul $\mathrm{C}_{21} \mathrm{H}_{24} \mathrm{O}_{4}$ berdasarkan analisis spektrum HRESIMS. Spektrum UV senyawa 1 dalam metanol memberikan serapan maksimum pada $\lambda_{\text {maks }}(\log \varepsilon): 287$ $(4,37)$ yang merupakan ciri khas senyawa pterokarpan (Tjahjandarie, 2015). Spektrum IR senyawa $\mathbf{1}$ dalam $\mathrm{KBr}$ memperlihatkan pita serapan pada $v_{\text {maks }}$ : 3402 (OH), 2948; 2864 (CH), 1602-1450 $(\mathrm{C}=\mathrm{C}$ aromatik) dan 1265 (eter). Spektrum 
${ }^{1} \mathrm{H}-\mathrm{NMR}$ (400 MHz, Tabel-1) senyawa 1 dalam $\mathrm{CDCl}_{3}$ memperlihatkan empat sinyal proton yakni sinyal triplet pada pergeseran kimia $\delta_{\mathrm{H}} 3,65(1 \mathrm{H}, t, J=11,0$ $\left.\mathrm{Hz}, \mathrm{H}-6_{\mathrm{ax}}\right), \delta_{\mathrm{H}} 4,22(1 \mathrm{H}, d d, J=11,0$ dan $\left.5,1 \mathrm{~Hz}, \mathrm{H}-6_{\mathrm{eq}}\right) ; \delta_{\mathrm{H}} 3,51(1 \mathrm{H}, m, \mathrm{H}-6 \mathrm{a})$ dan $\delta_{\mathrm{H}} 5,42(1 \mathrm{H}, d, J=6,8 \mathrm{~Hz}, \mathrm{H}-11 \mathrm{a})$ yang merupakan ciri khas dari kerangka struktur senyawa pterokarpan pada H-6, H-6a dan H-11a (Nguyen, 2010; Tjahjandarie, 2014). Spektrum ${ }^{1}$ H-NMR senyawa 1 memperlihatkan dua unit sinyal proton di daerah aromatik. Sepasang sinyal doublet $(J=8,1 \mathrm{~Hz})$ pada $\delta_{\mathrm{H}} 6,41(1 \mathrm{H}, \mathrm{H}-8)$ dan $\delta_{\mathrm{H}} 7,01(1 \mathrm{H}, \mathrm{H}-7)$ merupakan sinyal proton aromatik pada cincin $\mathrm{D}$ dari struktur pterokarpan. Sinyal proton aromarik sistem $\mathrm{ABX}$ pada cincin $\mathrm{A}$ terlihat pada $\delta_{\mathrm{H}} 7,40(1 \mathrm{H}, d, J=8,4 \mathrm{~Hz}$, $\mathrm{H}-1) \delta_{\mathrm{H}} 6,53(1 \mathrm{H}, d d, J=8,4$ dan $2,4 \mathrm{~Hz}$, $\mathrm{H}-2)$ dan $\delta_{\mathrm{H}} 6,40(1 \mathrm{H}, d, J=2,4 \mathrm{~Hz}, \mathrm{H}-4)$. Analisis spektrum ${ }^{1} \mathrm{H}-\mathrm{NMR}$ senyawa $\mathbf{1}$ memperlihatkan satu sinyal singlet metoksi pada $\delta_{\mathrm{H}} \quad 3,80 \quad\left(9-\mathrm{OCH}_{3}\right)$. Disamping itu juga, senyawa 1 memperlihatkan sinyal proton isoprenil yakni sinyal proton vinilik pada $\delta_{\mathrm{H}} 5,24$ $\left(1 \mathrm{H}, t, J=7,2 \mathrm{~Hz}, \mathrm{H}-2^{\prime}\right)$, sinyal metilen pada $\delta_{\mathrm{H}} 3,30\left(2 \mathrm{H}, d, J=6,8 \mathrm{~Hz}, \mathrm{H}-1^{\prime}\right)$ serta dua sinyal proton metil pada $\delta_{\mathrm{H}} 1,76$ $\left(3 \mathrm{H}, s, \mathrm{H}-4^{\prime}\right)$ dan $1,66\left(3 \mathrm{H}, s, \mathrm{H}-5^{\prime}\right)$. Spektrum ${ }^{13} \mathrm{C}$ NMR (percobaan APT, 100 $\mathrm{MHz}$ ) senyawa 1 memperlihatkan 21 sinyal atom karbon yang terpisah sempurna. Penempatan posisi hidroksi, metoksi dan isoprenil yang terikat pada inti aromatik senyawa $\mathbf{1}$ ditetapkan berdasarkan analisis HMQC dan HMBC. Dua sinyal proton pada $\delta_{\mathrm{H}} 3,65$ dan $\delta_{\mathrm{H}}$ 4,22 di H-6 memperlihatkan korelasi dengan dua sinyal karbon oksiaril pada $\delta_{\mathrm{C}}$
156,6 (C-4a), $\delta_{\mathrm{C}} 158,6$ (C-10a) serta dua sinyal karbon kuarterner pada $\delta_{\mathrm{C}} 40,0$ (C6a) dan $\delta_{\mathrm{C}} 78,0$ (C-11a). Sinyal proton aromatik pada $\delta_{\mathrm{H}} 7,40(\mathrm{H}-1)$ berkorelasi dengan dua sinyal karbon oksiaril pada $\delta_{\mathrm{C}}$ 156,6 (C-4a), $\delta_{\mathrm{C}} 157,1$ (C-3) serta satu sinyal karbon kuarterner pada $\delta_{\mathrm{C}} 78,0$ (C11a). Hasil ini menunjukkan gugus hidroksi terikat di C-3. Sinyal proton multiplet $\delta_{\mathrm{H}}$ 3,51 (H-6a) menunjukkan korelasi dengan satu sinyal karbon metilen pada $\delta_{\mathrm{C}} 66,6$ (C-6), satu sinyal karbon oksiaril pada $\delta_{\mathrm{C}} 158,6$ (C-10a), satu sinyal karbon kuarterner pada $\delta_{\mathrm{C}} 119,4$ (C-6b) dan satu sinyal karbon metin pada $\delta_{\mathrm{C}} 121,7$ (C-7). Hasil korelasi ini menunjukkan gugus metoksi dan isoprenil terikat di C-9 dan C-10. Sinyal proton aromatik pada $\delta_{\mathrm{H}}$ 7,01 (H-7) berkorelasi dengan dua sinyal karbon oksiaril pada $\delta_{\mathrm{C}} 158,5$ (C-9), 158,6 (C-10a) dan satu sinyal karbon kuarterner pada $\delta_{\mathrm{C}} 40,0$ (C-6a). Sinyal singlet metoksi pada $\delta_{\mathrm{H}} 3,80$ berkorelasi dengan $\delta_{\mathrm{C}} 158,5$ (C-9) dan mempertegas kedudukan metoksi terikat di C-9. Dengan demikian isoprenil terikat di C-10. Sinyal proton metilen dari isoprenil berkorelasi dengan satu sinyal karbon oksiaril pada $\delta_{\mathrm{C}} 158,6$ (C-10a), dua sinyal karbon kuarterner pada $\delta_{\mathrm{C}} 113,4(\mathrm{C}-10), \delta_{\mathrm{C}} 131,8$ (C-3') dan satu sinyal karbon metin pada $\delta_{\mathrm{C}} 122,4$ (C-2'). Berdasarkan analisis spektrum 1D dan 2D NMR maka struktur kimia senyawa 1 adalah 10-isoprenil-9-metoksi-3-hidroksi pterokarpan atau dikenal dengan nama sanwisensin (Tjahjandarie, 2014). Penempatan sinyal proton dan sinyal karbon senyawa 1 didukung oleh spektrum HMQC dan HMBC seperti terlihat pada Gambar 
Tabel 1. Data spektrum NMR senyawa sanwisensin (1) dalam $\mathrm{CDCl}_{3}$.

\begin{tabular}{|c|c|c|c|}
\hline No. $C$ & $\delta_{\mathrm{H}}($ mult, $J$ dalam Hz) & $\boldsymbol{\delta}_{\mathrm{C}}$ & HMBC \\
\hline 1 & $7,40(d, 8,4)$ & 132,5 & $\mathrm{C}-3 ; \mathrm{C}-4 \mathrm{a}, \mathrm{C}-11 \mathrm{a}$ \\
\hline 2 & $6,53(d d, 8,4 ; 2,4)$ & 109,9 & C-3; C-4; C-11b \\
\hline 3 & - & 157,1 & - \\
\hline 4 & $6,40(d, 2,4)$ & 103,2 & C-2; C-3; C-4a, C-11b \\
\hline $4 a$ & - & 156,6 & - \\
\hline \multirow[t]{2}{*}{6} & $4,22(d d, 11,0 ; 5,1)$ & 66,6 & C-4a; C-6a; C-6b, C-11a \\
\hline & $3,65(t, 11,0)$ & & \\
\hline $6 a$ & $3,51(m)$ & 40,0 & C-6; C-6b; C-7; C-10a \\
\hline $6 b$ & - & 119,4 & - \\
\hline 7 & $7,01(d, 8,1)$ & 121,7 & C-6a; C-9; C-10a \\
\hline 8 & $6,41(d, 8,1)$ & 103,6 & C-6b; C-9; C-10 \\
\hline 9 & - & 158,5 & - \\
\hline 10 & - & 113,4 & - \\
\hline $10 \mathrm{a}$ & - & 158,6 & - \\
\hline $11 \mathrm{a}$ & $5,42(d, 6,8)$ & 78,0 & C-1; C-4a. C-6; C-10 \\
\hline $11 \mathrm{~b}$ & - & 113,0 & - \\
\hline 1 ' & $3,30(d, 6,8)$ & 23,0 & C-10; C-10a; C-2'; C-3' \\
\hline $2^{\prime}$ & $5,24(t, 7,2)$ & 122,4 & C-10, C-2',C-3'; C-4'; C-5' \\
\hline 3 ' & - & 131,8 & - \\
\hline $4^{\prime}$ & $1,76(s)$ & 17,9 & $\mathrm{C}-2^{\prime} ; \mathrm{C}^{\prime} 3^{\prime} ; \mathrm{C}-5^{\prime}$ \\
\hline 5 & $1,66(s)$ & 25,9 & C-2'; C-3'; C-4' \\
\hline $9-\mathrm{OCH}_{3}$ & $3,80(s)$ & 56,1 & C-9 \\
\hline
\end{tabular}

Paseollin (2) berwujud padatan putih dan memperlihatkan ion kuasimolekul negatif $[\mathrm{M}-\mathrm{H}]^{-}$pada $\mathrm{m} / \mathrm{z}$ 321,1126 yang sesuai dengan rumus molekul $\mathrm{C}_{20} \mathrm{H}_{18} \mathrm{O}_{4}$ hasil pengukuran spektrum HRESIMS. Spektrum UV dan IR senyawa 2 dalam metanol memberikan serapan maksimum pada $\lambda_{\text {maks }}(\log \varepsilon): 313$ $(4,41) \quad \mathrm{nm}$ dan spektrum IR memperlihatkan pita serapan pada $v_{\text {maks: }}$ : 3433 (OH), 2948; $2901(\mathrm{CH}), 1628-1444$ $(\mathrm{C}=\mathrm{C}$ aromatik) dan 1213 (eter). yang mirip dengan senyawa 1. Spektrum ${ }^{1} \mathrm{H}-$ NMR senyawa 2 (Tabel-2) dalam $\mathrm{CDCl}_{3}$ memperlihatkan memperlihatkan empat sinyal proton pada H-6, H-6a dan H-11a yang mirip dengan senyawa 1.yakni pada $\delta_{\mathrm{H}} 3,60\left(1 \mathrm{H}, t, J=11,0 \mathrm{~Hz}, \mathrm{H}-6_{\mathrm{ax}}\right), \delta_{\mathrm{H}}$ $4,22\left(1 \mathrm{H}, d d, J=11,0\right.$ dan $\left.5,0 \mathrm{~Hz}, \mathrm{H}-6_{\mathrm{eq}}\right)$; $\delta_{\mathrm{H}} 3,48(1 \mathrm{H}, m, \mathrm{H}-6 \mathrm{a})$ dan $\delta_{\mathrm{H}} 5,48(1 \mathrm{H}, d$, $J=7,0 \mathrm{~Hz}, \mathrm{H}-11 \mathrm{a}$. Sepasang sinyal doublet $(J=8,0 \mathrm{~Hz})$ pada $\delta_{\mathrm{H}} 6,95$ dan $\delta_{\mathrm{H}}$ 6,34 di cincin D serta sinyal proton aromarik sistem $\mathrm{ABX}$ di cincin $\mathrm{A}$ pada $\delta_{\mathrm{H}}$ $7,41(1 \mathrm{H}, d, J=8,5 \mathrm{~Hz}, \mathrm{H}-1) \delta_{\mathrm{H}} 6,55(1 \mathrm{H}$, $d d, J=8,5$ dan $2,0 \mathrm{~Hz}, \mathrm{H}-2)$ dan $\delta_{\mathrm{H}} 6,41$ $(1 \mathrm{H}, d, J=2,0 \mathrm{~Hz}, \mathrm{H}-4)$. Spektrum ${ }^{1} \mathrm{H}-$ NMR memperlihatkan sepasang sinyal doublet cis vinilik $(J=10,0 \mathrm{~Hz})$ pada $\delta_{\mathrm{H}}$ 6,51 dan $\delta_{\mathrm{H}} 5,57$ serta dua sinyal singlet 
metil pada $\delta_{\mathrm{H}} 1,43$ dan $\delta_{\mathrm{H}} 1,40$ yang menunjukkan senyawa 2 mempunyai substituen cincin pirano. Spektrum ${ }^{13} \mathrm{C}$ NMR senyawa 2 memperlihatkan 20 sinyal atom karbon yang terpisah sempurna. Posisi gugus hidroksi dan berdasarkan analisis spektrum HMQC dan HMBC. Sinyal proton metilen di H-6 pada $\delta_{\mathrm{H}} \quad 3,60$ dan $\delta_{\mathrm{H}} \quad 4,22$ memperlihatkan korelasi yang sama dengan senyawa 1 yakni berkorelasi dengan dua sinyal karbon oksiaril pada $\delta_{\mathrm{C}} 156,7$ (C-4a), $\delta_{\mathrm{C}}$ 155,4 (C-10a) serta dua sinyal karbon kuarterner pada $\delta_{\mathrm{C}} 39,7$ (C-6a) dan $\delta_{\mathrm{C}} 78,7$ (C-11a). Sinyal proton aromatik di $\mathrm{H}-1$ yakni pada $\delta_{\mathrm{H}} \quad 7,40$ memperlihatkan korelasi dengan dua sinyal karbon oksiaril

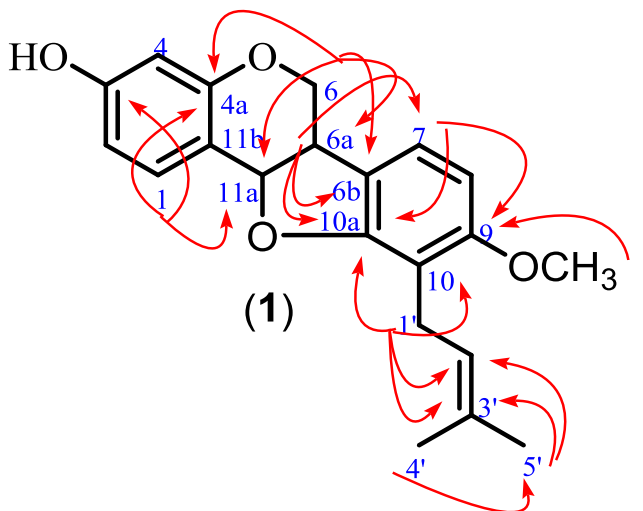
cincin pirano pada senyawa $\mathbf{2}$ ditetapkan

pada $\delta_{\mathrm{C}} 156,7(\mathrm{C}-4 \mathrm{a}), \delta_{\mathrm{C}} 157,1(\mathrm{C}-3)$ serta satu sinyal karbon kuarterner pada $\delta_{\mathrm{C}} 78,7$ (C-11a) dan menunjukkan posisi hidroksi terikat di C-3. Sinyal proton aromatik $\delta_{\mathrm{H}}$ 6,95 menunjukkan korelasi dengan dua sinyal karbon oksiaril yakni pada $\delta_{\mathrm{C}} 158,6$ (C-10a) dan $\delta_{\mathrm{C}} 153,7$ (C-9). Hasil korelasi ini menunjukkan cincin pirano terhubungkan di C-9 dan C-10. Berdasarkan analisis spektrum 1D dan 2D NMR maka struktur kimia senyawa 2 adalah 2',2'-dimetilpirano $\left[5^{\prime}, 6\right.$ '; 9,10] pterokarpan atau dikenal dengan paseollin (Tjahjandarie, 2014). Korelasi antara sinyal proton dengan sinyal karbon yang mendukung struktur senyawa $\mathbf{2}$ pada spektrum HMBC seperti terlihat pada Gambar 2.

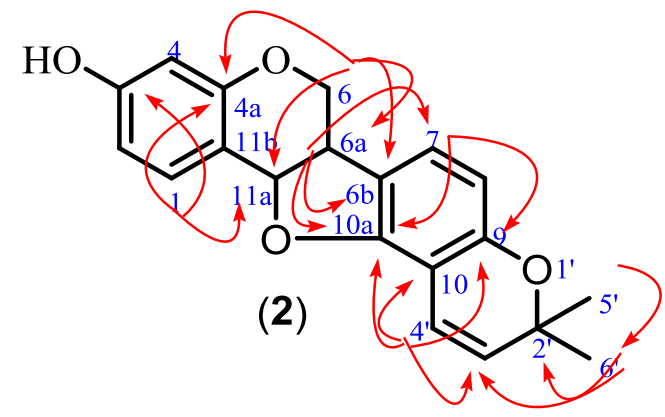

\section{Gambar 2. Korelasi HMBC yang utama pada senyawa 1-2}

Uji aktivitas antikanker senyawa sandwisensin (1) dan paseollin (2) terhadap sel murin leukemia P-388 memperlihatkan nilai konsentrasi daya hambat $\mathrm{IC}_{50}$ masing-masing senyawa sebesar 1,20 dan $1,05 \mu \mathrm{g} / \mathrm{ml} \mu \mathrm{g} / \mathrm{ml}$. Hasil aktivitas ini menunjukkan kedua senyawa pterokarpan mempunyai aktivitas antikanker yang sangat poten (Tjahjandarie, 2017). Siklisasi pada 2 dibanding senyawa $\mathbf{1}$ membentuk cincin pirano meningkatkan aktivitas antikanker.

Tabel 2. Data spektrum NMR senyawa paesollin (2) dalam $\mathrm{CDCl}_{3}$.

\begin{tabular}{llll}
\hline No. C & \multicolumn{1}{c}{$\boldsymbol{\delta}_{\mathbf{H}}($ mult, $\boldsymbol{J} \mathbf{H z})$} & $\boldsymbol{\delta}_{\mathbf{C}}$ & \multicolumn{1}{c}{ HMBC } \\
\hline 1 & $7,41(d, 8,5)$ & 132,3 & $\mathrm{C}-3 ; \mathrm{C}-4 \mathrm{a} ; \mathrm{C}-11 \mathrm{a}$ \\
2 & $6,55(d d, 8,5 ; 2,0)$ & 109,7 & $\mathrm{C}-4 ; \mathrm{C}-11 \mathrm{~b}$ \\
3 & - & 157,1 & - \\
4 & $6,41(d, 2,0)$ & 103,6 & $\mathrm{C}-2 ; \mathrm{C}-4 \mathrm{a} ; \mathrm{C}-11 \mathrm{~b}$ \\
$4 \mathrm{a}$ & - & 156,7 & - \\
\hline
\end{tabular}




\begin{tabular}{|c|c|c|c|}
\hline 6 & $\begin{array}{l}4,22(d d, 11,0 ; 5,0) \\
3,60(t, 11,0)\end{array}$ & 66,6 & C-4a; C-6a; C-6b; C-11a \\
\hline $6 a$ & $3,48(m)$ & 39,7 & C-6; C-6b; C-10a \\
\hline $6 b$ & - & 119,1 & - \\
\hline 7 & $6,95(d, 8,0)$ & 123,8 & C-9; C-10a \\
\hline 8 & $6,34(d, 8,0)$ & 106,2 & C-6b; C-9; C-10 \\
\hline 9 & - & 153,7 & - \\
\hline 10 & - & 106,2 & - \\
\hline $10 \mathrm{a}$ & - & 155,4 & - \\
\hline $11 \mathrm{a}$ & $5,48(d, 7,0)$ & 78,7 & C-1; C-4a; C-6; C-11b \\
\hline $11 b$ & - & 112,6 & - \\
\hline $1^{\prime}$ & - & - & - \\
\hline $2^{\prime}$ & - & 76,1 & - \\
\hline 3 ' & $5,57(d, 10,0)$ & 129,7 & C-10; C-4'; C-5'; C-6' \\
\hline $4{ }^{\prime}$ & $6,51(d, 10,0)$ & 116,5 & C-9; C-10; C-10a, C-3' \\
\hline 5 & $1,43(s)$ & 27,8 & C-2’; C-3’; C-6’ \\
\hline $6{ }^{\prime}$ & $1,40(s)$ & 27,7 & C-2'; C-3'; C-6’ \\
\hline
\end{tabular}

\section{KESIMPULAN}

Dua senyawa pterokarpan yakni sandwisensin (1) dan paseollin (2) telah berhasil diisolasi dari kulit batang E. fusca L.. Aktivitas antikanker senyawa sandwisensin (1) dan paseollin (2) terhadap sel murin leukemia P-388, keduanya menunjukkan aktivitas yang sangat poten.

\section{DAFTAR PUSTAKA}

Heyne, K., 1987. Tumbuhan Berguna Indonesia, Jilid II, Badan Penelitian dan Pengembangan Kehutanan, Departemen Kesehatan Republik Indonesia, Jakarta.

Innok, P., Rukachaisirikul, T., Phongpaichit, S., Suksamrarn, A., 2010, Fuscacarpans A-C, new pterocarpans from the stems of Erythrina fusca L. Fitoterapia, 81: 518-523.

Khaomek, P., Ichino, C., Ishiyama, A., Sekiguchi, H., Namatame, M., Ruangrungsi, N., Saifah, E.,
Kiyohara, H., Otoguro, K., Omura, S., Yamada, H., 2008, In vitro antimalarial activity of prenylated flavonoids from Erythrina fusca, $J$. Nat Med, 62: 217-220.

Nguyen, P.H., Le, T.V.T., Thuong, P.T., Dao, T.T., Ndinteh, D.T., Mbafor, J.T., Kang, K.K., Oh, W.K., 2009, Cytotoxic and PTP1B inhibitory activities from Erythrina abyssinica, Bioorg. Med. Chem. Lett., 19: 6745-6749.

Tanjung M, Hakim EH, Syah YM. 2017. Prenylated dihydrostilbenes from Macaranga rubiginosa. Chem Nat Compd. 53:215-218.

Tanjung, M., Saputri, R.D., Tjahjandarie, T.S., 2017. 4-Methoxy-3-(3methylbut-2-en-1-yl)-7-((3methylbut-2-en-1-yl)oxy) quinolin2(1H)-one from Melicope moluccana T.G. Hartley. Molbank. M939. 2: 1-5.

Tanjung M, Mujahidin D, Hakim EH, Darmawan A, Syah Y.M. 2010. 
Geranylated flavonols

from Macaranga rhizinoides. Nat

Prod Commun. 5:1209-1211.

Tjahjandarie, T.S.; Saputri, R.D.; Tanjung, M., $2017 . \quad 5,9,11-$

Trihydroxy-2,2-dimethyl-3-(2-

methylbut-3-en-2-yl)pyrano[2,3-a]

xanthen-12(2H)-one from the stem

bark of Calophyllum tetrapterum

Miq. Molbank, M936, 1: 1-5.

Tjahjandarie, T.S., Tanjung, M., 2015.

Lead compound antimalaria dan antioksidan senyawa alkaloid, flavonoid, dan kumarin dari Limonia accidisima L.. Laporan Akhir Penelitian Unggulan Perguruan Tinggi, Universitas Airlangga. 1-45.

Tjahjandarie, T.S., Tanjung, M., 2015.

Phenolic compounds from the stem bark of Erythrina orientalis and their cytotoxic and antioxidant activities. Der Pharma Chem, 7(1): 206-211.

Tjahjandarie, T.S., Pudjiastuti, P., Saputri, R.D., Tanjung, M., 2014. Antimalaria and antioxidant activity of phenolic compounds isolated from Erythrina crysta-galli L. J. Chem. Pharm. Res. 6: 786-790.

Yenesew, A., Induli, M., Derese, S., Midiwo, O.J., Heydenreich, M., Peter, G.M., Alaka, H., Wangui, J., Liyala, P., Waters, C.N., 2004, Anti-plasmodial flavonoids from the stem bark of Erythrina abyssinica, Phytochem. 65: 30293032. 